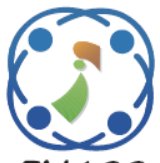

\title{
Application of Neural Modeling and the SPI Index for the Prediction of Weather Drought in the Saïss Plain (Northern Morocco)
}

\author{
Abdelhamid El Ibrahimi $^{1 *} \quad$ Abdennasser Baali $^{1}$ \\ ${ }^{1}$ Faculty of Sciences dher el mahrez, Department of geology, Laboratory of Geosystems, Environment and \\ Sustainable Development, Sidi Mohamed Ben Abdellah University, Fez, Morocco \\ * Corresponding author’s Email: abdelhamidsvt@gmail.com
}

\begin{abstract}
This contribution will verify the effectiveness of formal neural networks for predicting drought in a semiarid region using a hybrid model of formal neural networks (ANN-MLP) and the standardized precipitation index ( SPI). Three types of models have been optimized to achieve this objective. A database consisting of SPI values, rain, temperature and potential evapotranspiration (PET) at the monthly time step was used as input for these models. These data have been standardized between 0 and 1 and subdivided into two blocks: a first block composed of 2/3 of the data for learning and a second block composed of $1 / 3$ of the data for the test and the validation of the models. These models have been optimized with supervised learning. The activation function chosen is the logistic variant of the type sigmoid. The mean square error (RMSE), the correlation coefficient (R), the criterion of Nash-Sutcliffe (Nash) and the absolute mean error (MAE) were used to test the performance of these models. The results obtained show that the 3rd model is the most efficient. The application of neural networks for the estimation of the dryness of the Saïss Plain yielded quite good results. Indeed, the coefficients of correlation between the predicted and the measured values range from 0.63 to 0.97 . It is therefore noted that the performances obtained are relatively good and could be improved by using a larger database.
\end{abstract}

Keywords: Drought, Formal neural networks, SPI, RET, Temperature, Rain.

\section{Introduction}

Drought affects natural environment of an area when it persists for a longer period. So, drought forecasting plays an important role in the planning and management of natural resources and water resource systems of a river basin. During last decade neural networks have shown great ability in modeling and forecasting drought in Saïss Plain.

Over the last decades, artificial neural networks have a great ability to model and predict nonlinear and non-stationary time series in hydrology and water resource engineering due to their innate nonlinear property and their flexibility for modeling. Some of the benefits of NAS are [1]. (1) They are able to recognize the relationship between the input and output variables without explicit physical considerations. (2) They work well even when training sets contain noise and measurement errors.
(3) They are able to adapt to solutions over time to compensate for changing circumstances. (4) They possess other inherent information processing characteristics and once trained are easy to use. The neural network the models presented in this document is based on SPI as a drought index. The SPI is used in this study for the following advantages, which are discussed by [14]. The main reason is that SPI is based on rain only, so drought assessment is possible even if other hydrometeorological measurements are not available. The SPI is extremely disrupted by topography. Another advantage of SPI is its variable timing, which allows it to describe the severe drought conditions for a range of meteorological, hydrological and agricultural applications. The third advantage of SPI comes from its standardization, which ensures that the frequencies of extreme events at any place and on any time scale are consistent. SPI can also detect 
moisture deficiency deeper than the PDSI, which has a response time interval of about 8-12 months [14]. An application of ANN to solve civil engineering problems began in the late 1980s [2]. The preliminary concepts of artificial neural networks (ANNs) and their adaptability to hydrology are well explained [3].

Its application to simulation and forecasting problems in water resources has shown great capacity and some of the applications are mentioned here. Karunanithi et al. [4], have attempted to predict flow at the outlet of the current watershed with inputs such as precipitation, upstream flow and / or temperature only. Nagesh Kumar et al. [5], used recurrent neural networks to predict river flows. Pasini et al. [6], used a feed-forward neural network, formed by means of a backpropagation strategy using a generalized Widrow-Hoff rule to update the connection weights for the analysis of forced relationships / temperatures at different Scales of the climate system. Melesse and Hanley [7], used a feed-forward neural network using a back propagation algorithm in three different ecosystems (forest, grassland, and cultivated land) using shared energy fluxes, temperature Air and soil because the input variables for predicting the carbon flux are present. Sahoo et al. [8], used ANN to predict the occurrence of pesticides in rural household wells based on available information. Among the three ANN models (a backward propagation (BP), a radial basis function (RBF) and an adaptive neural network-based fuzzy inference system (ANFIS) used in this survey, the BP neural network Was found to be superior to RBF and ANFIS type networks for the detection of occurrences of pesticides in wells, Also the drawback ANFIS is sensitive to the initial number of fuzzy rules (number of clusters), the computational complexity develops as the number of fuzzy rules increases. Gevrey et al. [9], used a feed-forward multi-layer network using an error backpropagation training algorithm, investigated the exploratory capacity of variables to identify environmental factors affecting trout abundance, and how these factors contribute to Abundance of trout. However, a weakness also recognized for linear regression (MLR) and models of integral self-regressive progression (ARIMA). This limitation with non-stationary data has led to the recent formation of hybrid models, where the data are preprogrammed for non-stationary characteristics and then through a forecasting method such as ANNs to face the linear line. Support Vector Machines (SVM) are a relatively new form of machine learning developed by Vapnik [10]. The term SVM is used to designate both classification and regression methods as well as the terms Vector Classification (SVC) and Support Vector Regression (SVR), which refer to classification and regression problems respectively. The greatest limitation of the support vector approach lies in the choice of the kernel. The second limit concerns speed and size, both in the learning stage and in the test. Although SVMs have good generalization performance, they may be significantly slow in the test phase. There are several studies where SVR has been used in hydrological forecasts. ARMA models, pattern recognition techniques, physical models using the Palmer drought Severity Index (PDSI), standardized precipitation index (SPI), a moisture suitability index involving Markov chains or the concept Of conditional probability seem to offer A potential to develop reliable and robust forecasts [11]. Rao and Padmanabhane [12], studied the stochastic nature of the annual and monthly annual Palmer drought index (PDI) and used valid stochastic models to predict and simulate PDI series. Kim and Valdés [13], used PDSI as a drought parameter to predict a drought in the Conchos River basin in Mexico. The main objective of the current study is to calculate episodes of standardized precipitation index (SPI) for several time scales and to compare the neural network model with linear stochastic models to predict drought. The potential of models to predict drought over different horizons is discussed here.

\section{Methodology}

\subsection{Presentation of data used}

The data used in this article cover the period of January 1979 to December 2014 with a large database. These data are among others the potential evapotranspiration (PET), the real evapotranspiration (RET), rainfall and temperatures) these last two are obtained from the Agency of the Hydraulic Basin of Sebou (ABHS) concern respectively for those stations of Fez-DRH and FezSaiiss. For the monthly precipitation the extent of the series obtained is 35 years (1979 to 2014) with gaps. In fact, $10 \%$ of the data of rain collected are outliers. The work staff, is has calculated the SPI3, SPI6, SPI9, SPI12, SP24 and SPI48 by averaging the data of rainfall, the real evapotranspiration (RET) and PET used have been estimated using the method of Thornthwaite [15]. All these data have been observed in the monthly time step. Table 1 presents some characteristics of the stations selected for the study. 
Table 1. Characteristics of rainfall stations selected for the study

\begin{tabular}{|c|c|c|c|c|}
\hline \multirow{2}{*}{$\begin{array}{c}\text { The } \\
\text { stations }\end{array}$} & \multicolumn{2}{|c|}{$\begin{array}{c}\text { Lambert } \\
\text { coordinats }\end{array}$} & \multirow{2}{*}{$\begin{array}{c}\text { Altitude } \\
(\mathbf{m})\end{array}$} & $\begin{array}{c}\text { Scope } \\
\text { of } \\
\text { the } \\
\text { theries }\end{array}$ \\
\cline { 2 - 3 } X (km) & Y (km) & & $\begin{array}{c}1978- \\
2014\end{array}$ \\
\hline Fez - & 535.4 & 384.8 & 423 & $\begin{array}{c}1969- \\
\text { DRH }\end{array}$ \\
\hline $\begin{array}{c}\text { Ain- } \\
\text { Bittit }\end{array}$ & 538.200 & 370.250 & 450 & 2014 \\
\hline
\end{tabular}

Table 2. Variations of over lapping annual rainfall of the station of Fez-DRH during the period (1978-2014)

\begin{tabular}{|c|c|c|}
\hline Station & Fez - DRH & Ain-Bittit \\
\hline Minimum (mm) & 181 & 231,0 \\
\hline Maximum (mm) & 838 & 854,0 \\
\hline Average (mm) & 415,5 & 500,9 \\
\hline Écartype & 153 & 159,1 \\
\hline $\begin{array}{c}\text { Coefficient of } \\
\text { variation }\end{array}$ & $37 \%$ & $32 \%$ \\
\hline $\begin{array}{c}\text { Coefficient of } \\
\text { skewness }\end{array}$ & $85 \%$ & $57 \%$ \\
\hline
\end{tabular}

\subsection{Overview of formal neural networks}

A network of artificial neurons (ANN) can be defined as a mesh of several neurons (or cells), usually organized in layers [16, 17]. It is a powerful model to establish the complexity of the inputoutput relations of a system [18]. The neural network simulates the principle of functioning of the human brain which manages an information flow from a learning database [22]. Similarities were thus established between the elements of the biological neurons and the components of the formal or artificial neurons. It receives external variables descriptive of the state of the system through the inputs Xi. The connection between the NAs of order $i$ and $j$ is done through the weight Wij. The level of activation of the jth NA is modified by the weighted sum $\mathrm{Sj}$ of the weights of the n NA bonds located upstream. Then, in the second step, $\mathrm{Sj}$ is subjected to the application of the activation function "f", which is fixed for each NA according to the objectives of the modelization, in order to give a new activation threshold. These steps propagate between the input neurons until arriving at the output neurons to give the system its general appearance.

Several neural network architectures exist [14]. Multilayer perceptron (PMC) or radial function (RNF) type ANNs are commonly used to simulate nonlinear relationships [29]. In particular, the PMCs

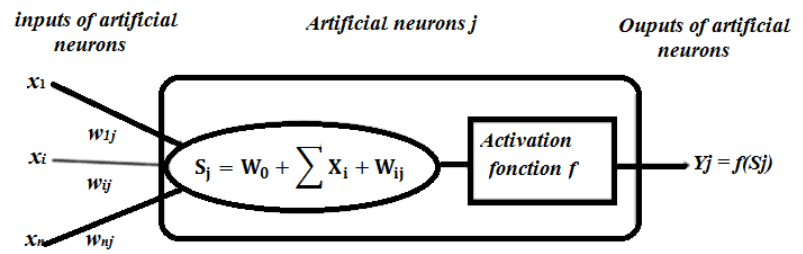

Figure.1 Schematization of a Formal neuron [21]

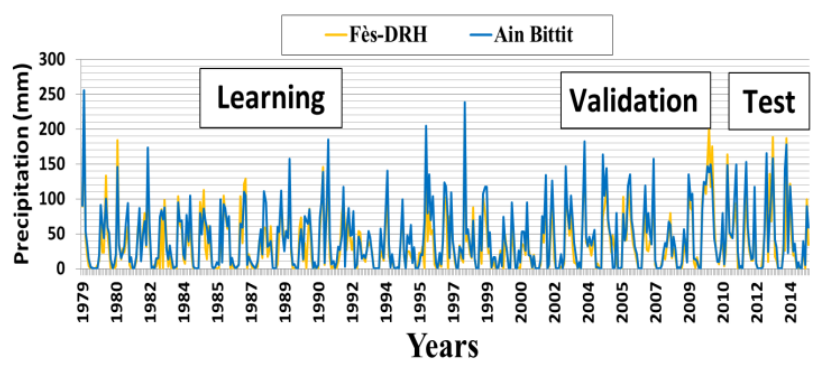

Figure. 2 Time series of monthly precipitation data for the two Fes-DRH and Ain Bittit stations for the period $1978 / 79$ to $2013 / 14$

are the most used and the most sophisticated [22] reason why they were chosen in the framework of this work. At the level of this architecture (PMC), each neuron in a layer is connected to all the neurons of the previous layer and the next layer and there are no connections between the cells of the same layer. Fig.4 shows a multilayer Perceptron with a single layer of hidden neurons. In this study, to avoid that during the learning of neural networks the smallest values have no influence and to ensure a convergence of the network the data have therefore been normed between 0 and 1 . This is done through 1 the following equation:

$$
\bar{x}=\frac{x-x_{\min }}{x_{\max }-x_{\min }}
$$

With: $\mathrm{x}$ is the actual value to be normalized, $\mathrm{x}$ min is its minimum value, $x$ max is its maximum value and $\mathrm{x}^{-}$is the normalized value. This transformation places the data of the input base between $[0,1]$.

Once the variables have been standardized, the $70 \%$ of the data will be chosen for the learning phase (model calibration), $15 \%$ for the test phase and the remaining $15 \%$ to validate the model. Neural networks are calibrated using iterative techniques. The most commonly used technique for calibration is the Broyden-Fletcher-GoldfarbShanno (BFGS) algorithm. Generally, it is gourmand in memory and requires a massive calculation. Nevertheless, it may require only a small number of iterations to calibrate an ANN by achieving a rapid convergence rate. 
Table 3. The values of the Standardized Precipitation Index (SPI) [20]

\begin{tabular}{|c|c|}
\hline Values of the SPI & Categories of drought \\
\hline 2.0 and more & Extremely damp \\
\hline 1.5 to 1.99 & Very wet \\
\hline 1.0 to 1.49 & Moderately Wet \\
\hline$-0,99$ to 0.99 & Close to the normal \\
\hline-1.0 to $-1,49$ & Moderately dry \\
\hline-1.5 to $-1,99$ & Very Dry \\
\hline-2 and less & Extremely dry \\
\hline
\end{tabular}

Table 4. The criterion of Nash-Sutcliffe and Category of the model

\begin{tabular}{|c|c|}
\hline $\begin{array}{c}\text { criterion of Nash- } \\
\text { Sutcliffe }\end{array}$ & Category of the model \\
\hline$\geq 90 \%$ & Excellent \\
\hline $80 \%$ to $90 \%$, & Very good \\
\hline $60 \%$ to $80 \%$, & Good \\
\hline$\leq 60 \%$ & Bad \\
\hline
\end{tabular}

Table 5. The Performance of the model according to the Correlation Coefficient

\begin{tabular}{|c|c|}
\hline $\begin{array}{c}\text { Correlation } \\
\text { Coefficient }\end{array}$ & Performance of the model \\
\hline $\mathrm{R}=1$ & Perfect \\
\hline $\mathrm{R}>0.8$ & Very high \\
\hline $0.5<\mathrm{R}<0.8$ & Strong \\
\hline $0.2<\mathrm{R}<0.5$ & Average \\
\hline $0<\mathrm{r}<0.2$ & Low \\
\hline $\mathrm{R}=0$ & Zero \\
\hline
\end{tabular}

$$
E_{\text {App }}=\sum_{i=1}^{n}\left(y_{\text {real }}-y_{\text {estim }}\right)
$$

With $\mathrm{E}_{\mathrm{App}}$ : Learning error, $\mathrm{y}$ real: calculated value, $\mathrm{y}$ estim: observed value and $\mathrm{n}$ : number of observations.

\subsection{Normalized precipitation index (SPI)}

The standardized precipitation index (SPI) [17] is a simple and robust index based both on rainfall data adopted by the World Meteorological Organization (WMO) [24] in 2009 as a global instrument for Measures of meteorological droughts. It can be used to check wet periods / cycles as well as dry periods / cycles. The SPI is applied to estimate the rainfall series of the two stations (FezDRH and Ain Bittit) for the period (1978-2014). However, at least monthly rainfall surveys over 20 to 30 years (preferably 50 to 60 years) are needed to calculate the SPI [25].

MCKEE [20] used the SPI index classification system (Tab.3) to define the intensity of drought episodes as a function of the index value. The mathematical formula of SPI is as follows:

$$
S P I=\frac{P_{i}-P_{m}}{\sigma}
$$

With Pi is the precipitation of year i, Pm is the mean precipitation and $\sigma$ is the deviation. They also defined the criteria for a drought event for any time scale:

\subsection{Evaluation of the performance of the models}

The performance of a model derived from a method of learning is assessed by its ability to prediction or of generalization [17]. In effect, the performance criteria to measure the quality or the confidence that can be given to the results of a forecast in view even, in a legal framework, a certification. The coefficient of determination $\left(\mathrm{R}^{2}\right)$, the mean square error (RMSE), the coefficient of Nash-Sutcliffe (NA), and the coefficient of correlation (r) have been used to compare the performance of the models and choose the best.

$$
\begin{gathered}
R=1-\frac{\sum_{i=1}^{N}\left(y_{0}-y_{e}\right)^{2}}{\sum_{i=1}^{N}\left(y_{0}-\bar{y}_{0}\right)^{2}} \\
R M S E=\sqrt{\frac{\sum_{i=1}^{N}\left(y_{0}-y_{e}\right)^{2}}{N}} \\
\text { Nash }=1-\frac{\sum_{i=1}^{N}\left(y_{e}-\bar{y}_{e}\right)^{2}}{\sum_{i=1}^{N}\left(y_{0}-\bar{y}_{0}\right)^{2}} \\
M A E=\frac{1}{N} \sum_{i=1}^{N}\left|y_{0}-y_{e}\right|
\end{gathered}
$$

The criterion of Nash-Sutcliffe varies from $-\infty$ to 1 and the following scale is generally used [18].

$$
r=\frac{\sum_{i=1}^{N}\left(y_{o}-\bar{y}_{0}\right)\left(y_{e}-\bar{y}_{e}\right)}{\sqrt{\sum_{i=1}^{N}\left(y_{0}-\bar{y}_{0}\right)^{2} \sum_{i=1}^{N}\left(y_{e}-\bar{y}_{e}\right)^{2}}}
$$

According to Koffi \& a [11] by convention. Where $y_{0}, y_{e}$ and $\mathrm{N}$ are SPI values observed, the values Estimated SPI and the number of data, respectively. In the coefficient of performance of the model, an efficiency of 1 corresponds to a perfect match of the data provided with the observed data. 


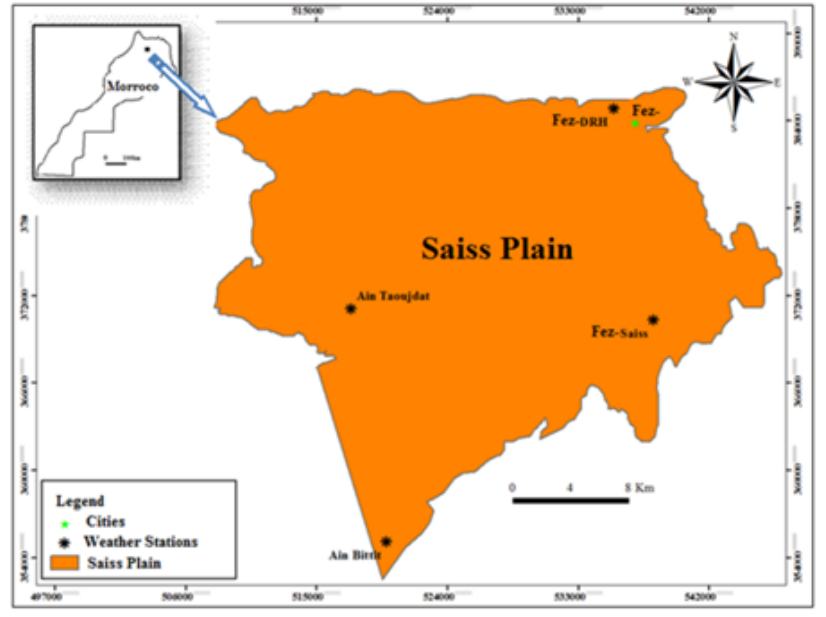

Figure.3 Geographical situation of the Saïss plain

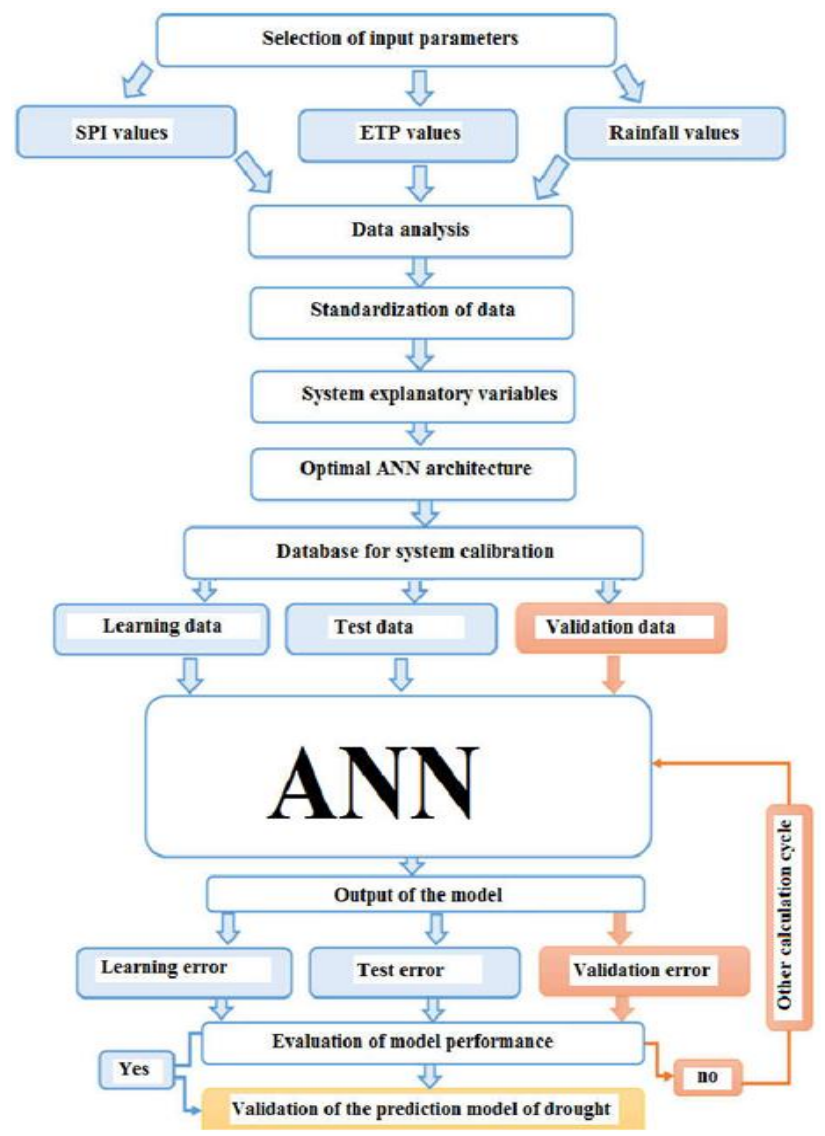

Figure.4 Structure of modeling by artificial neural networks applied to the prediction of drought

An efficiency of zero indicates that the predictions of the model are as accurate as the average of the observed data [20].

\subsection{Study area}

The Saïss Plain is part of the Fez-Meknes basin. The latter is located in the north of Morocco between the Middle Atlas in the south and the preHainan hills in the north with a total area of around
$6000 \mathrm{~km} 2$ (Lambert coordinates: $467<\mathrm{X}<552 \mathrm{~km}$ and $320<\mathrm{Y}<390 \mathrm{~km}$ ).

Because of its geographical location between two mountainous areas in northern Morocco, according to the Sebou Hydraulic Basin Agency (ABHS), the region is characterized by a Mediterranean climate with a semi-arid climate in temperate and humid winter and been hot and dry in a semi-continental diet. Rainfall is one of the most useful parameters for defining different climatic parameters.

The average annual precipitation of the basin is on average $600 \mathrm{~mm}$ with a maximum of $1000 \mathrm{~mm}$ on the height further north in the rif and a minimum of $300 \mathrm{~mm}$ and the valleys of the Beht. In the Saïss basin, the average annual maximum temperature is $23{ }^{\circ} \mathrm{C}$, while the minimum temperature is $11^{\circ} \mathrm{C}$ [27].

\subsection{Design of the model}

The characterization of drought by explanatory factors is an axial step for the design of a neural model for modeling. In this part we approach the prediction of meteorological drought from a simulated model. There must first be an effective data collection system that will provide us with the quality of the data. It must then be able to represent these data efficiently and compatible with the subsequent processing steps.

The steps in the development of the ANN model are listed in Fig.4.

\section{Results and analysis}

During the course of this study has been conducted in the development of four models (ANN-MLP1, ANN-MLP2, ANN-MLP3, ANNMLP4) for the prediction of the SPI that differ by the number and types of variables of entries. The evaluation of the modeling has been performed from the results of the validation. Table 6 illustrates the different Results evaluated according to the criteria of digital performance (MAE, RMSE, R and Nash).

For a forecast of SPI $(t+1)$ (Table 6), the Nash criterion does not show a significant difference. This brings us to compare the models through the criteria RMSE, MAE and $R$. These criteria indicate satisfactory results and eligible for all combinations with the exception of Model ANN-MLP1.

The ANN model the more efficient is the model Number 5 with the architecture ANN-MLP5 (12-41) (Fig. 5) with variables of rains, SPI and FTE of the month $\mathrm{t}$ and the 2 previous months ( $\mathrm{t}-1)$ and $(\mathrm{t}-2)$. 
Table 6. Performance of 4 models of neural networks developed

\begin{tabular}{|c|c|c|c|c|c|c|c|}
\hline \multirow{3}{*}{$\begin{array}{l}\text { The models } \\
\text { ANN -MLP }\end{array}$} & \multirow{3}{*}{ Inputs of the model } & \multicolumn{6}{|c|}{ Validation } \\
\hline & & \multirow{2}{*}{ MAE } & \multirow{2}{*}{ RMSE } & \multicolumn{2}{|c|}{$\mathbf{R}$} & \multicolumn{2}{|c|}{ Nash } \\
\hline & & & & Value & Model & Value & Model \\
\hline ANN-MLP1 & $\mathrm{P}(\mathrm{t}), \mathrm{P}(\mathrm{t}-1), \mathrm{P}(\mathrm{t}-2)$ & 0.698 & 0.835 & 0.055 & Low & $27 \%$ & $\mathrm{Bad}$ \\
\hline \multirow{2}{*}{ ANN -MLP2 } & $\mathrm{P}(\mathrm{t}), \mathrm{P}(\mathrm{t}-1), \mathrm{P}(\mathrm{t}-2)$ & \multirow{2}{*}{0.247} & \multirow{2}{*}{0.497} & \multirow{2}{*}{0.806} & \multirow{2}{*}{$\begin{array}{l}\text { Very } \\
\text { hard }\end{array}$} & \multirow{2}{*}{$64.63 \%$} & \multirow{2}{*}{ Good } \\
\hline & SPI $(\mathrm{t}), \mathrm{SPI}(\mathrm{t}-1), \mathrm{SPI}(\mathrm{t}-2)$ & & & & & & \\
\hline \multirow{3}{*}{ ANN -MLP3 } & $\mathrm{P}(\mathrm{t}), \mathrm{P}(\mathrm{t}-1), \mathrm{P}(\mathrm{t}-2)$ & \multirow{3}{*}{0.242} & \multirow{3}{*}{0.492} & \multirow{3}{*}{0.811} & \multirow{3}{*}{$\begin{array}{l}\text { Very } \\
\text { hard }\end{array}$} & \multirow{3}{*}{$65.32 \%$} & \multirow{3}{*}{ Good } \\
\hline & SPI $(\mathrm{t}), \mathrm{SPI}(\mathrm{t}-1), \mathrm{SPI}(\mathrm{t}-2)$ & & & & & & \\
\hline & PET $(\mathrm{t}), \operatorname{PET}(\mathrm{t}-1), \operatorname{PET}(\mathrm{t}-2)$ & & & & & & \\
\hline \multirow{3}{*}{ ANN -MLP4 } & $\mathrm{P}(\mathrm{t}), \mathrm{P}(\mathrm{t}-1), \mathrm{P}(\mathrm{t}-2)$ & \multirow{3}{*}{0.234} & \multirow{3}{*}{0.24} & \multirow{3}{*}{0.820} & \multirow{3}{*}{$\begin{array}{l}\text { Very } \\
\text { hard }\end{array}$} & \multirow{3}{*}{$66.48 \%$} & \multirow{3}{*}{ Good } \\
\hline & SPI(t), SPI(t-1), SPI (t-2); & & & & & & \\
\hline & $\mathrm{T}(\mathrm{t}), \mathrm{T}(\mathrm{t}-1), \mathrm{T}(\mathrm{t}-2)$ & & & & & & \\
\hline \multirow{4}{*}{ ANN-MLP5 } & $\mathrm{P}(\mathrm{t}), \mathrm{P}(\mathrm{t}-1), \mathrm{P}(\mathrm{t}-2)$ & \multirow{4}{*}{0.211} & \multirow{4}{*}{0.459} & \multirow{4}{*}{0.836} & \multirow{4}{*}{$\begin{array}{l}\text { Very } \\
\text { hard }\end{array}$} & \multirow{4}{*}{$69.80 \%$} & \multirow{4}{*}{ Good } \\
\hline & SPI(t), SPI(t-1), SPI (t-2); & & & & & & \\
\hline & PET(t), PET(t-1), PET(t-2); & & & & & & \\
\hline & $\mathrm{T}(\mathrm{t}), \mathrm{T}(\mathrm{t}-1), \mathrm{T}(\mathrm{t}-2)$ & & & & & & \\
\hline
\end{tabular}

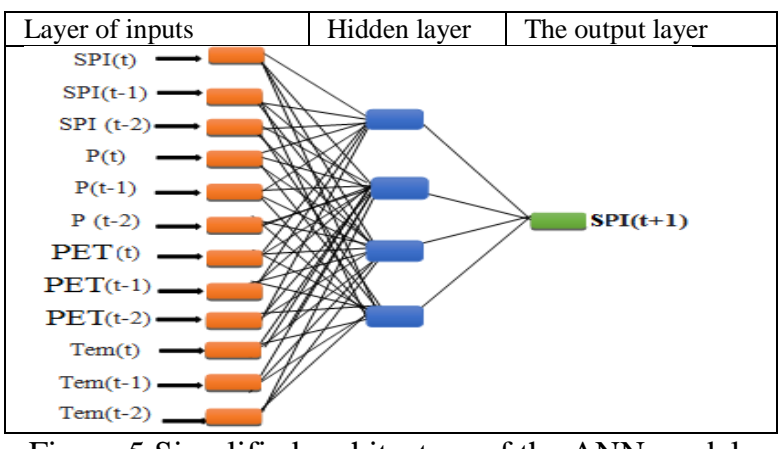

Figure.5 Simplified architecture of the ANN modelMLP5 retained for the prediction of drought, with a single layer of hidden neurons

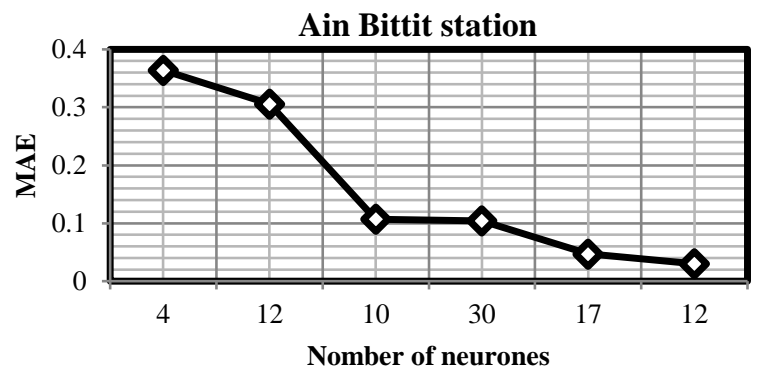

Figure.6 Variation of the number of neurons in the hidden layer according to the MAE criterion for the station Ain Bittit

In fact, the addition of the information of the temperature (tem) and the PET to the rainfall $(\mathrm{P})$ in a same model of prediction of drought changes their influences vis-a-vis this model as well as the results products. The different combinations have produced an ANN model improved compared to the other (Tables 7 and 6).

The Optimal architectures and the forecasts of the ANN model-MLP5 by comparison of actual values and the predicted values for the two stations

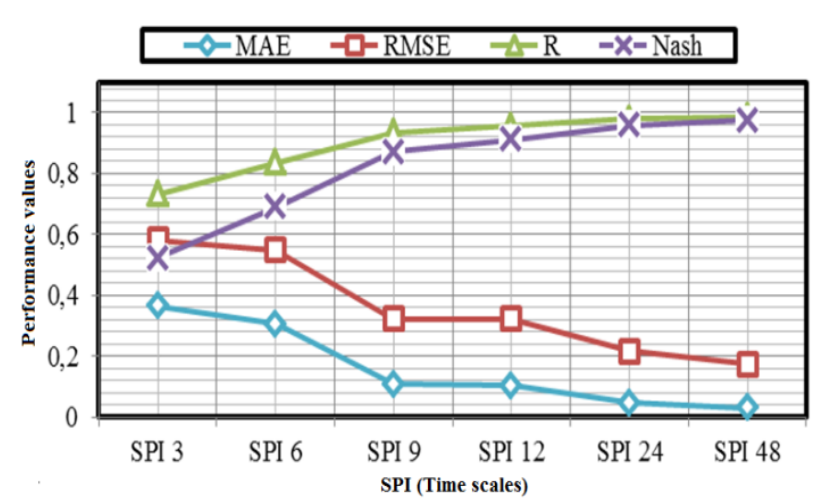

Figure.7 Comparison of performance criteria with SPI at different time scales at the Fez-DRH station level

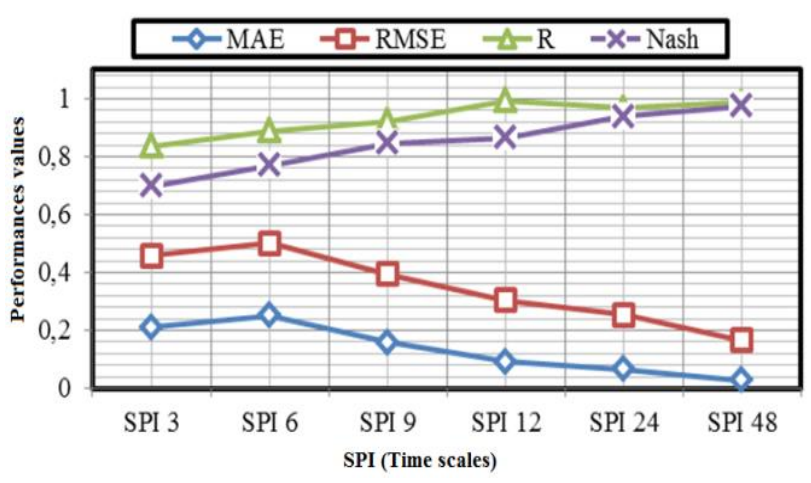

Figure.8 Comparison of performance criteria with SPI at different time scales at the Ain Bittit station level

Fez-HRD and Ain Bittit for SPI to different time windows and models are presented in (Tables 7 and 8).

For the number of neurons in the hidden layer, it must be optimized using the available data. To do this, the process was by trial and error based on the measurement of the absolute value average (MAE) for data used to test for each model. Fig. 6 shows the variation in the number of neurons in the 
Table 7. Results of the prediction of SPI values at different time-scales for the model of RNA-MLP5 in the station FezDRH

\begin{tabular}{|c|c|c|c|c|c|c|}
\hline & \multicolumn{6}{|c|}{ SPI on different time scales } \\
\hline & SPI 3 & SPI 6 & SPI 9 & SPI 12 & SPI 24 & SPI 48 \\
\hline Architecture & $12-4-1$ & $12-29-1$ & $12-29-1$ & $12-4-1$ & $12-4-1$ & $12-17-1$ \\
\hline MAE & 0.211 & 0.251 & 0.158 & 0.091 & 0.066 & 0.027 \\
\hline RMSE & 0.459 & 0.501 & 0.395 & 0.303 & 0.254 & 0.165 \\
\hline \multirow[t]{2}{*}{$\overline{\mathbf{R}}$} & 0.836 & 0.890 & 0.923 & 0.993 & 0.969 & 0.987 \\
\hline & Very hard & Very hard & Very hard & Very hard & Very hard & Very hard \\
\hline \multirow[t]{2}{*}{ Nash } & $69.80 \%$ & $77.11 \%$ & $84.76 \%$ & $86.64 \%$ & $94.02 \%$ & $97.57 \%$ \\
\hline & Good & Good & Very good & Very good & Excellent & Excellent \\
\hline
\end{tabular}

Table 8. Results of the prediction of SPI values at different time-scales for the model of ANN-MLP5 in the station Ain Bittit

\begin{tabular}{|l|l|l|l|l|l|l|}
\hline & \multicolumn{7}{|c|}{ SPI on different time scales } \\
\cline { 2 - 7 } & SPI 3 & SPI 6 & SPI 9 & SPI 12 & SPI 24 & SPI 48 \\
\hline Architecture & $12-4-1$ & $12-12-1$ & $12-10-1$ & $12-30-1$ & $12-17-1$ & $12-12-1$ \\
\hline MAE & 0.364 & 0.306 & 0.107 & 0.104 & 0.047 & 0.030 \\
\hline RMSE & 0.581 In & 0.497 & 0.322 & 0.323 & 0.217 & 0.173 \\
\hline \multirow{2}{*}{ Nash } & 0.732 & 0.835 & 0.934 & 0.956 & 0.980 & 0.988 \\
\cline { 2 - 7 } & Fort & Very hard & Very hard & Very hard & Very hard & Very hard \\
\hline & $52.31 \%$ & $68.94 \%$ & $87.21 \%$ & $91.15 \%$ & $95.77 \%$ & 99.04 \\
\cline { 2 - 7 } & Bad & Good & Very good & Excellent & Excellent & Excellent \\
\hline
\end{tabular}

hidden layer as a function of the criterion MAE for the station Ain Bittit for the SPI models developed and shows that, 12 neurons in the hidden layer is the optimal number.

To see the evolution of the performance indicators based on the SP time window), the results of the table ( 7 and 8 ) have been transformed into the following two graphs (Figs. 7 and 8).

Fig. 9 shows the comparison of the simulated and observed data of SPI which forms a cloud of points situated around the linear straight line for the test phase of the model. The results obtained show a significant agreement illustrated by a high correlation coefficient, with the exception of SPI3 and SPI6, which indicate average performances between observed and predicted values. It is also found that the correlation between the predicted values and the observed values of the model increases significantly at a higher time scale. This can be explained by way of the time series SPI is calculated. Unlike the series of precipitation, SPI follows a standard normal distribution. This sudden conversion eliminates peaks leaving a slowly variable smooth curve that is easier to predict by using neural network models.

\section{Discussion}

Similar studies have shown that the more data available for learning, the more faithfully the models would reproduce the flows. Among these studies, we can mention those of [28] on the forecasting of flows of the Apalachicola River (Florida, USA) with the Artificial Neural Networks. Indeed, these authors predicted flows at several time steps (daily, monthly, quarterly and yearly) and obtained respective Pearson correlation coefficients of 0.98 ; $0.95 ; 0.91$ and 0.83 . The analysis of these performances shows that the smaller the time step considered, which is equivalent to a large number of data, the developed forecast models appear to perform better. The work of [23] also concluded that the more input data from neural networks are, the more efficient these models are.

The poor prediction by neural networks in studies could be due to the separation of calibration bases and validation. A random separation could improve the performance of these models. In our case, the application of neural networks for the estimation of the dryness of the Saïss plain has yielded quite good results. Indeed, the coefficients of correlation between the predicted and the measured values range from 0.63 to 0.97 . It is therefore noted that the performances obtained are relatively good and could be improved by using a larger database. The choice of good quality explanatory variables could also lead to better results

Indeed, a multilayered Perceptron, with a single hidden layer and a few neurons are sufficient to make the prediction of the drought at the level of the Saïss Plain, with good performances. The number of 
neurons 4 for the Fez-DRH station and 12 for the Ain Bittit station on the hidden layers of the developed networks gave impressive results. From this study, rainfall and potential evapotranspiration with temperature are sufficient as inputs of the Multilayered Perceptron Directed to predicting droughts in a semi-arid climate.

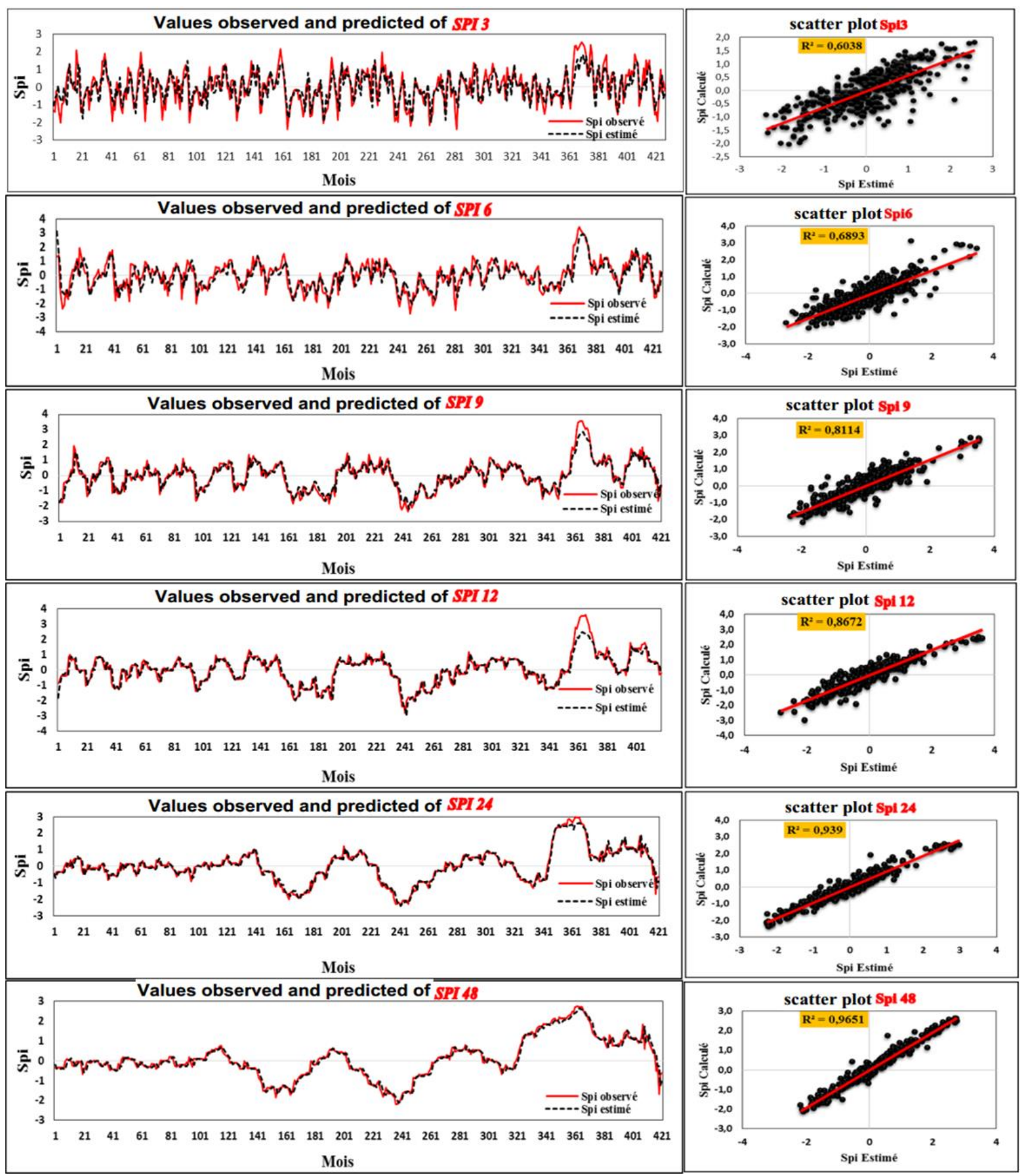

Figure.9 Comparison between SPI measured values and SPI values predicted for Fez station -DRH 


\section{Conclusion}

This study attempted to determine the most efficient model for forecasts of the drought SPI index in the Saïss Plain in Morocco. The ANNMLP5 model has proven to be the most efficient model for SPI 3 to SPI 12 prediction at both weather stations. The model showed a greater correlation between the observed SPI and the predicted SPI compared to the other models. Thus, the ANNMLP5 model also consistently displayed lower RMSE and AEM values compared to the other models in this study. The model selected showed enhanced forecasting results for SPI 12 compared to SPI 3.

Forecast results deteriorated with the increase in forecasting time for all models. ANN methods have proved their effectiveness in the prediction of SPI as automatic learning techniques. This trend has occurred in the Saiiss Plain and should be studied in other regions and should be compared with other techniques to determine if ANNs are the most effective tools for predicting drought versus models. Future studies should attempt to explore WaveletANN models with wavelet decompositions, and explore SPI predictions using these new methods in other regions with different characteristics. Future studies should also try to quantify time change error, as it is part of the forecasting problems with regression models.

\section{References}

[1] ASCE Task Committee on Application of Artificial Neural Networks in Hydrology, "Artificial neural networks in hydrology. II. Hydrologic applications", $J$. Hydrol. Eng., Vol.5, No.2, pp.115-123, 2000.

[2] I. Flood, and N. Kartam, "Neural networks in civil engineering, I. Principles and understanding", J. Comput. Civil Eng. ASCE, Vol.8, No.2, pp.149-162, 1994.

[3] R.S. Govindaraju, and A.R. Rao, (Eds.), "Artificial Neural Networks in Hydrology", Kluwer Academic Publishers, Amsterdam, the Netherlands, 2000.

[4] N. Karunanithi, W.J. Grenney, D. Whitely, and K. Bovee, "Neural networks for river flow prediction", J. Comput. Civil Eng. ASCE, Vol.8 No.2, pp.201-220, 1994.

[5] D. Nagesh Kumar, K.S. Raju, and T. Satish, "River flow forecasting using recurrent neural networks", Water Resour. Manage, Vol.18, pp.141-163, 2004.
[6] A. Pasini, M. Lore, and F. Ameli, "Neural network modelling for the analysis of forcings/temperatures relationships at different scales in the climate system", Ecol. Model, Vol.191, pp.58-67, 2006.

[7] A.M. Melesse, and R.S. Hanley, "Artificial neural network application for multi-ecosystem carbon flux simulation", Ecol. Model, Vol.189, pp.305-314, 2005.

[8] G.B. Sahoo, C. Ray, and H.F. Wade, "Pesticide prediction in ground water in North Carolina domestic wells using artificial neural networks", Ecol. Model, Vol.183, pp.29-46, 2005.

[9] M. Gevrey, I. Dimopoulos, and S. Lek, "Review and comparison of methods to study the contribution of variables in artificial neural network models", Ecol. Model, Vol.160, pp.249-264, 2003.

[10] V. Vapnik, "The Nature of Statistical Learning Theory", Springer Verlag, New York, USA, 1995.

[11] U.S. Panu, and T.C. Sharma, "Challenges in drought research: some perspectives and future directions", Hydrol. Sci., 47S, 2002.

[12] A.R. Rao, and G. Padmanabhan, "Analysis and modelling of palmers drought index series", $J$. Hydrol., Vol.68, pp.211-229,1984.

[13] T. Kim, and J.B. Valdes, "Nonlinear model for drought forecasting based on a conjunction of wavelet transforms and neural networks", $J$. Hydrol. Eng. ASCE, Vol.8, No.6, pp.319-328, 2003.

[14] M.J. Hayes, M.D. Svoboda, D.A. Wilhite, and O.V. Vanyarkho, "Monitoring the 1996 drought using the standardized precipitation index", Bull. Am. Meterol. Soc., Vol.80, pp.429-438, 1999.

[15] C.W.Thornthwaite "An approach toward a rational classification of climate. The geographical Review, Vol. XXXVIII, No.1, p. 55-94, 1948.

[16] g. Dreyfus, M. Samuelides, J. Martinez, M. Gordon, F. Badran, S.Thiria and L. Herault "Réseaux de neurones - Méthodologies et applications", ÉDITIONS EYROLLES, Paris, France, p.200, 2004.

[17] Y. B. Koffi, and al, "Modélisation des valeurs en eau potable dans les capitales africaines au sud du Sahara: application des réseaux de neurones formels à la ville de Yamoussoukro, capitale politique de la cote d'ivoire", Journal of Asian Scientific Research, Vol.2, No.10, pp.562-573, Vol.17, No.3, pp. 313-328, 2010.

[18] Y. Najjar, I. Basheern, and M. Hajmeer, "Computational Neural Network for predictive 
microbiology: Methodology", International Journal of food microbiology, Vol.34, pp.27- 49, 1997.

[19] S. Piechowiak, "Intelligence Artificielle et diagnostic", In Techniques De L'ingénieur (Ed.), Collection des Techniques de l'Ingénieur, Techniques de l'Ingénieur, Paris, pp.1-20, 2004.

[20] C. TOUZET, "Les réseaux de neurones artificiels. Introduction au connexionnisme", Cours, exercice et travaux pratiques, p.58,1992.

[21] I. Zaier, C. Shu, T. Ouarda, O. Seidou, and F. Chebana, "Estimation of ice thickness on lakes using artificial neural network ensembles", $J$. Hydrol., Vol.383, No.3-4, pp.330-340, 2010.

[22] S. Lallahem, J. Mania, A. Hani, and Y. Najjar, "On the Use of Neural Networks for evaluate groundwater levels in fractured media", Note soumise au $J$ of Hydrology, 2002.

[23] T.B. Mckee, N.J. Doesken, and J. Kleist, "The relationship of drought frequency and duration to time scales", In: Proc. of the 8th Conference on Applied Climatology, pp.179-184,1993.

[24] World Meteorological Organization (WMO), "Guide d'utilisation de l'indice normalisé de précipitations", (M. Svoboda, M. Hayes et D. Wood) (OMM-N ${ }^{\circ}$ 1090), Genève, 2012.

[25] N.B. Guttman, "Comparing the Palmer drought index and the standardized precipitation index", J. Am. Water Resour. Assoc., Vol.34, No.1, pp.113-121, 1998.

[26] I. Pulido-Calvo, and J.C. Gutierrez, "Improved irrigation water demand forecasting using a soft computing hybrid model", Biosyst Eng., Vol.102, No.2, pp.202-218, 2009.

[27] ABHS (Agence du bassin hydraulique du Sebou). Débat Nationale sur l'eau. Rapport., p.48, 2006.

[28] P. Besse, "Data mining II. Modélisation Statistique \& Apprentissage", Publications du laboratoire de statistique et probabilité. Université Paul Sabatier, Toulouse, p.103, 2005.

[29] W. S. Mcculloch and W. Pitts, "A logical calculus of the ideas immanent in nervous activity", Vol.5, pp.115-133, 1943. 